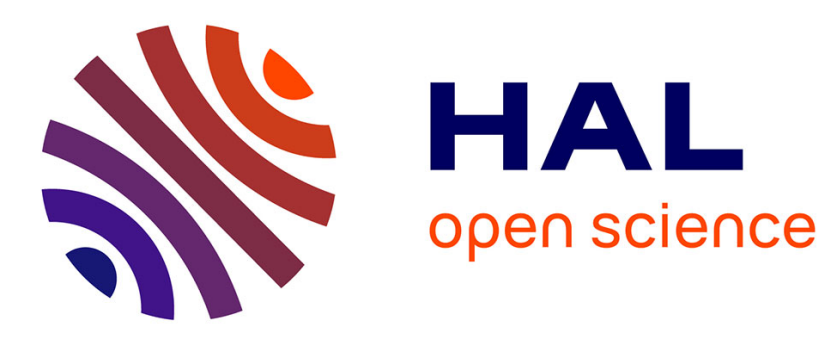

\title{
Lifecycle Management in the Smart City Context: Smart Parking Use-Case
}

\author{
Ahmed Hefnawy, Mohammed Taha Elhariri Essamlali, Abdelaziz Bouras, \\ Chantal Cherifi, Jérémy Robert, Sylvain Kubler, Kary Främling
}

\section{To cite this version:}

Ahmed Hefnawy, Mohammed Taha Elhariri Essamlali, Abdelaziz Bouras, Chantal Cherifi, Jérémy Robert, et al.. Lifecycle Management in the Smart City Context: Smart Parking Use-Case. 13th IFIP International Conference on Product Lifecycle Management (PLM 2016), Jul 2016, Columbia, SC, United States. pp.631-641, 10.1007/978-3-319-54660-5_56 . hal-01531772

\section{HAL Id: hal-01531772 \\ https://hal.science/hal-01531772}

Submitted on 1 Jun 2017

HAL is a multi-disciplinary open access archive for the deposit and dissemination of scientific research documents, whether they are published or not. The documents may come from teaching and research institutions in France or abroad, or from public or private research centers.
L'archive ouverte pluridisciplinaire HAL, est destinée au dépôt et à la diffusion de documents scientifiques de niveau recherche, publiés ou non, émanant des établissements d'enseignement et de recherche français ou étrangers, des laboratoires publics ou privés. 


\title{
Lifecycle Management in the Smart City Context: Smart Parking Use-Case
}

\author{
Ahmed Hefnawy ${ }^{1,3}$, Taha Elhariri ${ }^{1}$, Abdelaziz Bouras ${ }^{2,3}$, Chantal Cherifi ${ }^{1}$, \\ Jeremy Robert ${ }^{4}$, Sylvain Kubler ${ }^{4}$, Kary Främling ${ }^{5}$ \\ ${ }^{1}$ DISP Lab, Université Lumière Lyon 2, Lyon, France \\ \{firstname.lastname\}@univ-lyon2.fr \\ ${ }^{2}$ DCSE, College of Engineering, Qatar University, Qatar \\ \{firstname.lastname\}@qu.edu.qa \\ ${ }^{3}$ Ministry of Transport and Communications (MoTC), Qatar \\ ${ }^{4}$ Interdisciplinary Centre for Security, Reliability and Trust, University of Luxembourg, \\ Luxembourg \\ \{firstname.lastname\}@uni.lu \\ ${ }^{5}$ Aalto School of Science and Technology, Finland \\ \{firstname.lastname\}@aalto.fi
}

\begin{abstract}
Lifecycle management enables enterprises to manage their products, services or product-service bundles. IoT and CPS have made products and services smarter by closing the loop of data across different phases of lifecycle. Similarly, CPS and IoT empower cities with real-time decision-making capabilities enabled by real-time data streams from heterogeneous objects. Yet, cities are smarter and more powerful when relevant data can be exchanged between different systems across different domains. From engineering perspective, smart city can be seen as a System of Systems (SoS) composed of interrelated/ interdependent smart systems and objects. To better integrate people, processes, and systems in the smart city ecosystem, this paper discusses the use of PLM/ SLM to better manage smart cities. Considering the differences between ordinary and smart service systems, this paper seeks better understanding of lifecycle aspects in the smart city context. As a proof-ofconcept, the proposed approach is applied to a smart parking use-case.
\end{abstract}

Keywords: PLM, SLM, CL2M, SoS, Smart City.

\section{Introduction}

Lifecycle Management is a concept [1] that evolved in 1990s to improve several engineering aspects of an enterprise to manage its products across their lifecycles [2]. As per J. Li et al. [3], Product Lifecycle Management (PLM) is ideally used to manage the knowledge intensive process consisting mainly of market analysis, product design and process development, product manufacturing, distribution, product in use, post-sale service, and recycling. Despite what its name implies, PLM is not only about manufactured products; J. Stark [4] extends the definition of "product" to include services, package of services or a bundle of products and services. O. Isaksson et al. [5] also see "service" as part of the wider concept of "product". 
The transformation from product-oriented to more service-oriented economies is part of a complete "servitization" revolution, with more than $70 \%$ of global workers engaged in service tasks [6]. Therefore, traditional product-centric sectors evolve into service-centric sectors in order to meet the new challenges, with the aim to put customers and users at the center of their business models [7]. Through servitization, companies seek unique selling proposition for their products, in which the physical artifact is extended by a surrounding provision of services, thus defining the concept of Product-Service System (PSS) [8]. J. Cassina et al. [9] call PSS as extended product, where the product is a complex result of tangible and intangible components.

The advancement of ICT and the evolve of Internet of Things (IoT) and Cyber Physical Systems (CPS) have made ordinary products smarter. D. Kiritsis [10] argues that smart products allow monitoring new parameters of the product and its environment along different phases of lifecycle. In this regard, the PROMISE, an EUfunded FP6 project, provides a mean to transfer critical information about a product back and forward across the lifecycle, and O-MI/ O-DF standards emerged out of this project [11]. Similarly, IoT and CPS have an enabling role in public services in the city environment, and can exist in many forms [12]. The simplest form of CPS is the form of single objects, like sensors and actuators that collect data and execute commands respectively. CPS can also be in the form of smart systems that address domain-specific issues, like transportation, parking, energy, lightening, etc.

As it was proposed in previous research in [12], [13] and [14], and in line with ambitions of many cities and states around the world, there is a need for a more holistic vision of smart city as a complete ecosystem. This paper carries on the proposed lifecycle approach to ensure systematic involvement and seamless flow of information between different stakeholders of the smart city ecosystem. Nevertheless, this holistic vision of smart city implies interrelations and interdependence between multiple smart systems that in many cases are independently developed, operated and managed [15]. Hence this paper proposes a step further to extend lifecycle functionalities to smart cities, in order to exchange not only generated data but also system data, versions, variants and business processes. This research aims to understand some lifecycle aspects in the smart city context, considering some features like heterogeneity of data sources, interdependence between smart systems and integration between cyber and physical components.

The remainder of this paper consists of four sections. Section 2 includes related work of different types of lifecycle management. Section 3 projects lifecycle management aspects on smart city systems and explains the proposed meaning of different lifecycle components and functionalities in the smart city context. Section 4 demonstrates the lifecycle approach in a smart parking use-case. Section 5 includes discussion of this paper and the proposed future work.

\section{Related Work}

The term Lifecycle management has been mostly associated with "product", in Product Lifecycle Management (PLM) and "service", in Service Lifecycle Management (SLM). In addition, Lifecycle management is a very crucial aspect of 
Product-Service Systems (PSS), in which a manufacturing company sets its market proposition on extending the traditional functionality of its products by incorporating additional services for reaching new market competitive advantages [6].

PLM. A product is defined as an output that results from a process. Products can be tangible or intangible, a thing or an idea, hardware or software, information or knowledge, a process or procedure, a service or function, or a concept or creation (ISO 9001:2000) [5]. PLM is commonly referred to as a strategic approach that incorporates the management of data associated with products of a particular type, and perhaps the versions and variants of that product type, as well as the business processes that surround it [11]. PLM has three main phases [2]: Beginning of Life (BOL), Middle of Life (MOL), and End of Life (EOL). BOL is the period in which product concept is generated, designed, and subsequently physically realized. MOL is the period when products are distributed, used, and maintained by customers or engineers. EOL is the period when products are recycled by manufacturers or disposed [3].

SLM. Service can be a product in itself, when it comes under the ISO definition of product. C. Sassanelli et al. [6] define "service" as an activity done for others with an economic value and often done on a commercial basis. SLM is conceptually similar to PLM, however it manages the lifecycle of services instead of tangible products. SLM can be characterized by the same three main phases, like PLM: BOL, MOL, and EOL [16] [17]. BOL consists of service ideation, definition, design, test and service system implementation. MOL consists of service delivery and service system maintenance. EOL consists of service redesign and service system decommission.

PSS. C. Sassanelli et al. [6] define "system" as a collection of elements including their relations. As part of the servitization trend, manufacturing companies extend their traditional products by incorporating additional services. This approach supports the development of service-oriented sectors, switching the emphasis from the "sale of products" to the "sale of use" and reshaping the same concept of customer values, from "possession" to "utilization" [6] [26]. From business perspective, the traditional boundaries between manufacturing and services are blurring. Additionally, business models have dramatically changed. Manufacturers provide and guarantee functions/ solutions instead of products; ownership stays with manufacturers; hence, efficient use, maintenance and repair, in MOL, are becoming prevailing in the value chain [5].

CL2M. The objective of Closed-Loop Lifecycle Management is to allow information flow management to go beyond the customer, to close the product lifecycle information loops, and to enable seamless e-transformation of product lifecycle information to knowledge [10]. D. Kiritsis argues that a closed-loop PLM system allows all the actors who play a role during the lifecycle of a product (managers, designers, service and maintenance operators, recyclers, etc.) to track, manage and control product information at any phase of its lifecycle, at any time and any place [10]. As per K. Främling et al. [11], CL2M contribute to enhancing various aspects of PLM, particularly the following: (1) information manageability: to efficiently and properly process large amount of data; (2) information interoperability: to manage the many changes in data media and formats and to ensure information exchanges between any kind of products, users, and systems; (3) information visibility: to make data available for any system, anywhere, and at any time. 


\section{Smart City Lifecycle Management}

Smart city is a composition of smart objects, smart systems, and smart services that focus on problems and issues that arise in service sectors, like transport, logistics, energy, waste management [18] [19]. Yet, smart city as a complete ecosystem goes beyond conventional product systems, service systems or PSS [20] [21]; and hence, Smart City Lifecycle Management (SCLM) has some differences from ordinary PLM/ SLM, in terms of components, description and functionalities. As proposed in [14] and shown in Fig. 1, Lifecycle Management can be used in the smart city context to manage data, versions, variants and business processes associated with heterogeneous, uniquely identified connected objects.

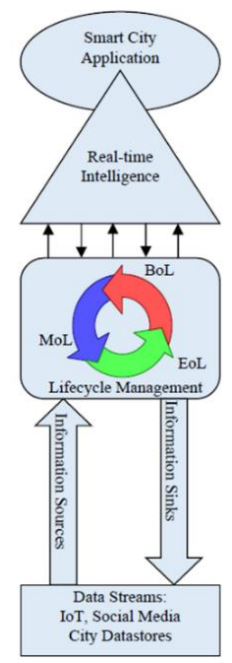

Fig. 1. Smart City: High-Level Conceptual Model [14].

Smart City as a SoS. Smart city is a SoS, where individual, heterogeneous, functional service systems are linked together and organized in a hierarchy of subsystems to realize new features/ functionalities [15] [17]. For example, A. Medvedev et al. [20], propose a smart waste collection system that enable dynamic scheduling and routing of waste trucks. The proposed system features data exchange between waste management, surveillance/ monitoring and transportation/ routing smart systems. Another example, J. Poncela, et al. [19] propose a CCTV camera video stream to feed to a video processing algorithm that extracts information such as numbers of cars/people/objects in a given street. Authors propose a middleware layer for selection and discovery of the appropriate data sources.

SCLM phases. To allow evolutionary development of smart city, in most cases, smart city is composed of independently developed, operated and managed service systems. Therefore, SCLM has no clear phases similar to PLM/ SLM; instead, each component of the smart city has its own lifecycle; and, smart city components can be at different phases - BOL, MOL and EOL - in the same time. Therefore, the lifecycle of smart city is in fact a lifecycle of lifecycles [22]. 
Bill of Materials(BOM). BOM is a hierarchical structure showing the components that make up the end item [14]. The end item in this case can be a smart city service system or a smart city SoS. In the smart city context, smart objects can be repurposed and reused [23]. As shown in the above examples, monitoring cameras were used for smart waste management as well as smart transportation, although the initial purpose is to be used in surveillance system. Therefore, BOM in the smart city context should allow for loose-coupling, modularity, composability, scalability interdependency and dynamic complexity [24] [25].

Product/ Service/ System data. The interdependence between different smart systems in the smart city context, as detailed in hierarchy structure of BOM, gives the right to interdependent systems to exchange product/ service/ system data that should be generated and used across lifecycle phases. The large scale of smart city will produce large amounts of data across lifecycle. Archiving and traceability requirements vary from one industry to another. Unique identification of every component is very crucial for traceability. Product/ Service/ System data can be in various states, including in-work, in-process, in-review, released, as-designed, asplanned, as-built, as-installed, as-maintained, and as operated [14].

Ownership and Rights. Ownership in the smart city context is an important issue. In light of heterogeneity, repurposing and reusing of data sources, certain components can belong to multiple smart systems. Due to the dynamic complexity of smart city, rights may change during lifecycle. Rights include rights to access, create and modify data, and also rights to approve and promote.

Policies and Regulations. Smart city is subject to many policies and regulations related to the different utilities infrastructure, public services and applications. Cyber security, resiliency of ICT connectivity infrastructure and user data privacy are of absolute importance.

Versions, Variants and Options. During SCLM phases, smart city components can be modified or upgraded. Particularly software components in CPS. Hence, smart city components can have multiple versions, options, variants, releases and alternatives.

Processes. Processes include problem report process, engineering change process and enterprise notification process. For these processes, it's absolutely important to define actors and roles. In the smart city context, processes can include notifications, verifications and approvals between actors from different domains.

\section{Smart Parking: Use-Case}

This section carries on the use-case, presented in [13], for smart parking system. This is a hypothetical scenario that was built as a proof-of-concept. The proposed scenario was examined in collaboration with the on-going H2020 project named "bIoTope". to use the O-MI/ O-DF standards to exchange data between different nodes in the proposed smart parking system. Meanwhile, Aras Innovator ${ }^{\circledR}$ was used to examine some PLM functionalities in the proposed case. This paper will only focus on the lifecycle aspect of the smart parking system.

${ }^{1}$ http://biotope.cs.hut.fi/ 
As detailed in [13], the proposed smart parking system allocates parking spaces to users, based on the preferred entrance and eligibility to use allocated spots for people with disability. In this paper, we propose to use smart parking systems in FIFA World Cup 2022 stadia in Qatar. The main functions of the proposed system include: booking of parking spaces in-advance through online booking; parking space allocation as close as possible to entrance leading to the booked seat; fast track car entrance through gates that are equipped with plate number reader and only open to eligible cars; another plate number reading at each parking space to alert user in case of parking in a wrong space (not the allocated parking space). Fig. 2 presents the high-level illustration of the proposed smart parking system.

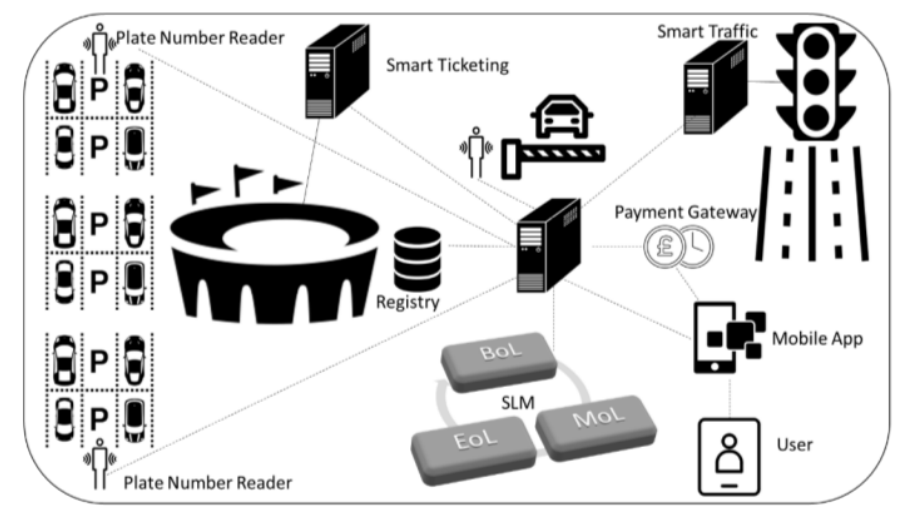

Fig. 2. Smart Parking: High-level Illustration.

BOM. To develop the BOM, we detailed a hierarchical structure of the components that make up the smart parking system. The smart parking system was structured in zones $(1 \ldots n)$; each zone has one gate equipped with plate number reader; and certain number of parking spaces $(1 \ldots \mathrm{j})$, each has its plate number reader. Fig. 3 shows a snapshot from BOM. Aras Innovator ${ }^{\circledR}$ was used for two purposes, first is to build and manage BOM; second is to export BOM in O-DF structure as XML file to build O-DF object tree. Fig. 3 is a screenshot from Aras Innovator ${ }^{\circledR}$, showing the user interface for smart parking system; and Fig. 4 shows the implementation of the O-DF structure into the smart parking O-MI node which relies on the first reference implementation of O-MI/ O-DF standards. Hence, Aras Innovator ${ }^{\circledR}$ can be used as a master tool to manage all lifecycle aspects including BOM development and changes in case of new versions and/ or variants.

Versions, variants and options. As a step further in the smart parking use-case, this part discusses potential scenarios for new versions, variants and options. For this purpose, we denoted the smart parking system, as explained above, as version (V 1.0). After implementing ( $\mathrm{V}$ 1.0) in a number of stadia that will host the world cup competitions, it was noticed that some users park in parking spaces different than their allocated ones, disregarding the red light alert. Problem Reports (PRs) were developed by parking zone administrators in three different stadia reporting the same problem. PRs were reviewed and verified by chief of staff in stadia. The manager of smart parking has approved PRs, as per the PR process shown in Fig. 5. 


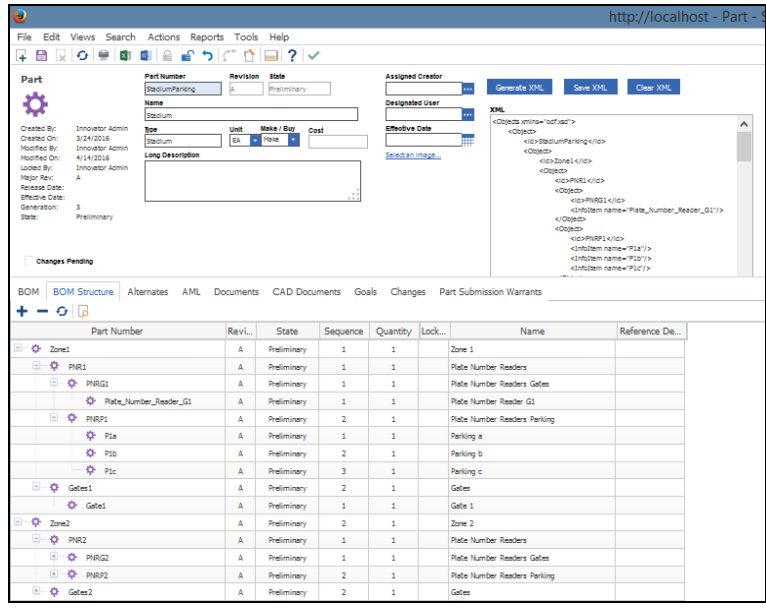

Fig. 3. BOM: Screenshot from Aras Innovator®.

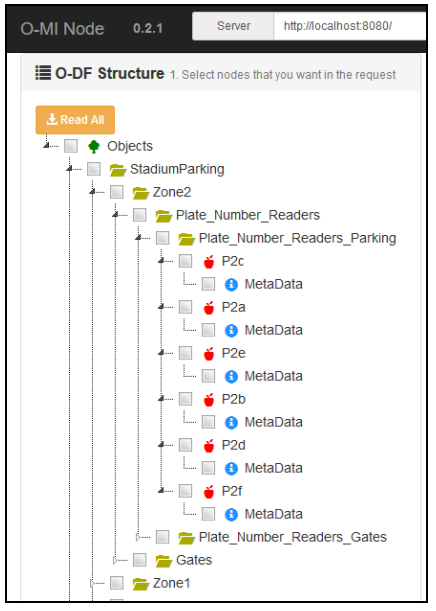

Fig. 4. O-DF Object Tree.

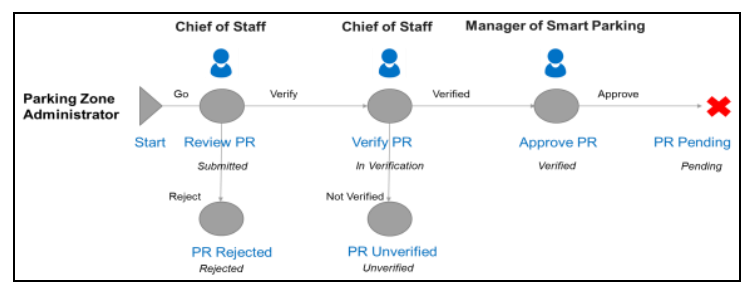

Fig. 5. PR process.

As a response to the above mentioned PRs, an Engineering Change Request (ECR) was developed to overcome the violent parking, as per the ECR process shown in Fig. 6. The proposed solution was to add surveillance cameras to monitor violent parking cars in order to file cases against these cars. One stadium has rejected the ECR and decided to keep (V 1.0) smart parking system while dealing with the PR by increasing the number of security personnel who can immediately intervene and request violent cars to use their allocated parking spaces. The second stadium has approved the ECR through a fast track approval. Hence, the smart parking system evolved to version ( $\mathrm{V}$ 2.0); accordingly, the BOM should be updated by adding 1 camera to each parking zone. The third stadium has approved the ECR and requested to add an option to connect the smart parking system with the traffic department system so that the applicable fine will go directly to the traffic department upon capturing the violent car. Hence, a new variant of smart parking will evolve (V 2.1). due to the relationship with other systems, the ECR in the last scenario should go through the Change Request Board (CRB) approval route that involve all relevant stakeholders. 
The Enterprise Change Notice $(\mathrm{ECN})$ is a process by which changes are implemented within the smart parking system, as shown in Fig. 7. The change, in case of $(\mathrm{V} 2.0)$ and the variant $(\mathrm{V} 2.1)$ is the addition of cameras, as new parts, to all parking zones. The ECN process is used to take the new parts from preliminary lifecycle state to a released lifecycle state. The relevant PRs and ECR can be attached to the ECN for tracking and reporting. Aras Innovator ${ }^{\circledR}$ was used to manage PRs, ECR and ECN processes and update the BOM accordingly.

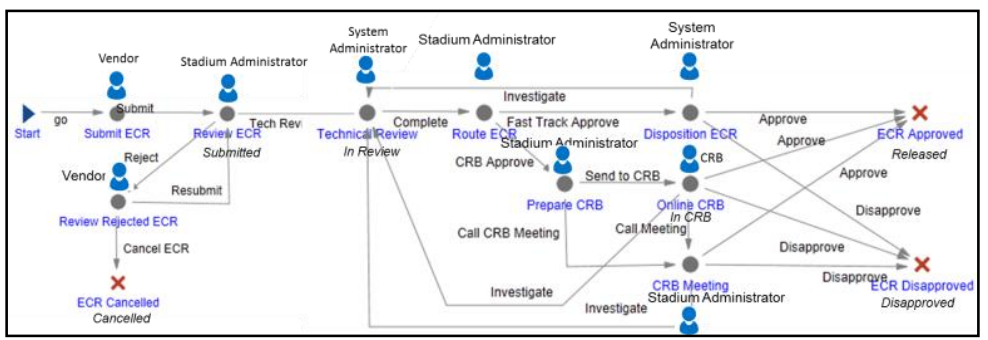

Fig. 6. ECR Workflow Process.

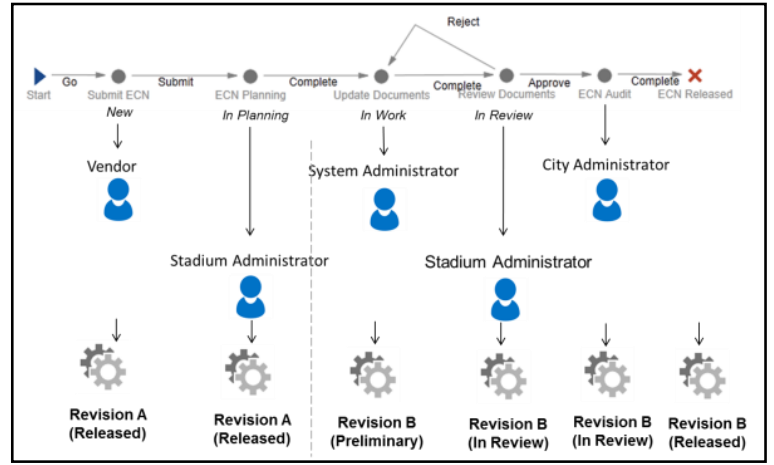

Fig. 7. ECN Workflow Process.

\section{$5 \quad$ Discussion and Future Work}

As lifecycle management has enabled large enterprises to better manage their products, services and product-service bundles; similarly, lifecycle management can enable city operators to better manage public services and supporting infrastructure. The wide spread of IoT technologies and CPS systems in the city environment closes lifecycle data/ information loops across different phases and between heterogeneous objects/ systems. From engineering perspective, smart city as a service system has some features like: heterogeneity and loose-coupling of data sources; complexity of systems and composability of parts; customer oriented and service based systems. These features require some distinctions between lifecycle management in the smart city context, and PLM and SLM. 
The vision of applying lifecycle management in the smart city domain(s) is to better integrate people, processes, and systems; and assure information consistency, traceability, and long-term archiving. To achieve such a holistic vision of complete smart city ecosystem, there is a need for two types of data to be exchanged. First, data collected from heterogeneous data sources that can be used in different domains. Second, system data that include BOM, versions, variants, stats and other lifecycle related data. The conducted proof-of-concept has shown good level of integration between lifecycle management tool and the O-MI node tool to exchange the two types of data. Future work will include expanding the use-case to ensure exchange of the two types of data between different systems in the smart city. Another required effort is to build general smart city BOM that includes as much as possible categories and parts that compose a smart city.

\section{References}

1. H. ZHANG, A. SEKHARI, Y. OUZROUT, A. BOURAS. "PLM components monitoring framework for SMEs based on a PLM maturity model and FAHP methodology" Journal of Modern Project Management, Volume 2. $\mathrm{N}^{\circ} 1$, Pages 109119, 2014.

2. H. Zhang, Y. Ouzrout, A. Bouras, M. Savino. "Sustainability consideration within Product Lifecycle Management through Maturity Models Analysis". Int. J. Services and Operations Management. Volume 19, Issue 2. 2014.

3. J. Li, F. Tao, Ying Cheng, L. Zhao. "Big Data in product lifecycle management". International Journal Advanced Manufacturing Technologies, Volume 81, Issue 1, Pages 667-684. 2015

4. J. Stark. "Product Lifecycle Management: 21 century paradigm for product realization". 2nd edition. 2011.

5. O. Isaksson, T.C. Larsson and A. Öhrwall Rönnbäck. "Development of ProductService Systems: Challenges and Opportunities for the Manufacturing Firm”. Journal of Engineering Design; Special Issue on Product-Service Systems; Volume 20, Issue 4, pages 329-348, 2009.

6. C. Sassanelli, G. Pezzottac, M. Rossi, S. Terzia, S. Cavalieric. "Towards a Lean Product Service Systems (PSS) Design: state of the art, opportunities and challenges". Procedia CIRP Volume 30, Pages 191-196, December 2015.

7. M. Freitag, D. Kremer, M. Hirsch, M. Zelm. "An Approach to standardize a Service Life Cycle Management". Enterprise Interoperability, John Wiley \& Sons, Ltd, Chichester, UK. 2013.

8. M. Garetti, P. Rosa, S. Terzi. "Life Cycle Simulation for the design of ProductService Systems". Computers in Industry Volume 63, Pages 361-369. 2013.

9. J. Cassina, A. Cannata, M. Taisch. "Development of an Extended Product Lifecycle Management through Service Oriented Architecture". The 1st CIRP Industrial Product-Service Systems (IPS2) Conference, Cranfield University, 1-2 April 2009.

10. Kiritsis. "Closed-loop PLM for intelligent products in the era of the internet of things". Computer-Aided Design. 2010.

11. K. Främling, S. Kubler, A. Buda. "Universal Messaging Standards for the IoT from a Lifecycle Management Perspective". IEEE Internet of Things Journal, Volume 1, Issue 4, Page 319 - 327. 2014. 
12. A. Hefnawy, A. Bouras and C. Cherifi. "Lifecycle Based Modeling of Smart City Ecosystem". IKE'15: The 14th International Conference on Information \& Knowledge Engineering, Las Vegas 27-30 Jul. 2015.

13. A. Hefnawy, A. Bouras and C. Cherifi. "IoT for Smart City Services: Lifecycle Approach". The International Conference on Internet of things and Cloud Computing (ICC 2016), Cambridge 22-23 March 2016.

14. A. Hefnawy, A. Bouras and C. Cherifi. "Integration of Smart City and Lifecycle Concepts for Enhanced large-scale Event Management". IFIP PLM'15 International Conference, Doha 19-21 Oct. 2015.

15. J. Lopes and R. Pineda. "Service Systems Engineering Applications". Conference on Systems Engineering Research (CSER' 13). March 19-22, 2013.

16. F. Mahut, M. Bricogne, J. Daaboul, B. Eynard. "Servicization of Product Lifecycle Management: towards Service Lifecycle Management”. IFIP PLM'15 International Conference, Doha 19-21 Oct. 2015.

17. M. Freitag, S. Stadler. "Requirements for a Service Lifecycle Management" Conference Paper: Fraunhofer IAO. January 2013.

18. S. Cavalieri, G. Pezzotta. "Product-Service Systems Engineering: State of the art and research challenges". Computers in Industry, Volume 63, Issue 4, Pages 278-288, May 2012.

19. J. Poncela, et al. "Smart Cities via Data Aggregation". Wireless Personal Communications. Volume 76, Issue 2, pp 149-168. May 2014.

20. J. Jin, J. Gubbi, S. Marusic, M. Palaniswami. "An Information Framework for Creating a Smart City through Internet of Things". IEEE Internet of Things Journal, Vol. 1, No. 2, April 2014.

21. J. Sum. "Service Systems Engineering: Framework \& Systems Modeling”. Institute of Technology Management, National Chung Hsing University Taichung 40227, Taiwan ROC. January 2014.

22. BKCASE Editorial Board. "The Guide to the Systems Engineering Body of Knowledge (SEBoK)". v.1.3. R.D. Adcock (EIC). Hoboken, NJ: The Trustees of the Stevens Institute of Technology. 2014.

23. F. Tao, Y. Zuo, L. Xu, L. Lv, L. Zhang. "Internet of Things and BOM-Based Life Cycle Assessment of Energy-Saving and Emission-Reduction of Products". IEEE Transactions on Industrial Informatics, Volume 10, No. 2, MAY 2014.

24. T. Böhmann, J. Leimeister, K. Möslein. "Service Systems Engineering". Business \& Information Systems Engineering. DOI 10.1007/s12599-014-0314-8. Pages 73 - 79. February 2014.

25. S. Silcher, J. Minguez, T. Scheibler, B. Mitschang. "A Service-Based Approach for Next-Generation Product Lifecycle Management”. IEEE IRI 2010, Las Vegas, Nevada, USA, August 4-6, 2010.

26. D. Schmidt, O. Malaschewski, D. Fluhr, M. Mörtl. "Customer-oriented Framework for Product-Service Systems". 7th Industrial Product-Service Systems Conference PSS, industry transformation for sustainability and business. Procedia CIRP 30 (2015). Pages: 287 - 292. 2015.

27. IEEE-Reliability Society. Technical Committee on "Systems of Systems" - White Paper. October 2014. 